Article

\title{
Iminopyridine Ni(II) Catalysts Affording Oily Hyperbranched Ethylene Oligomers and/or Crystalline Polyethylenes Depending on the Reaction Conditions: Possible Role of In Situ Catalyst Structure Modifications
}

\author{
Ilaria D'Auria (D), Zeinab Saki (D) and Claudio Pellecchia *(D) \\ Dipartimento di Chimica e Biologia "A. Zambelli", Università di Salerno, 84084 Fisciano, Italy; \\ ildauria@unisa.it (I.D.); zsaki@unisa.it (Z.S.) \\ * Correspondence: cpellecchia@unisa.it
}

Citation: D'Auria, I.; Saki, Z.; Pellecchia, C. Iminopyridine Ni(II) Catalysts Affording Oily Hyperbranched Ethylene Oligomers and/or Crystalline Polyethylenes Depending on the Reaction

Conditions: Possible Role of In Situ Catalyst Structure Modifications. Macromol 2021, 1, 121-129. https:// doi.org/10.3390/macromol1020010

Academic Editor: Ana

María Díez-Pascual

Received: 23 March 2021

Accepted: 28 April 2021

Published: 7 May 2021

Publisher's Note: MDPI stays neutral with regard to jurisdictional claims in published maps and institutional affiliations.

Copyright: (c) 2021 by the authors. Licensee MDPI, Basel, Switzerland. This article is an open access article distributed under the terms and conditions of the Creative Commons Attribution (CC BY) license (https:/ / creativecommons.org/licenses/by/ $4.0 /)$.

\begin{abstract}
Nickel-based ethylene polymerization catalysts have unique features, being able to produce macromolecules with a variable content of branches, resulting in polymers ranging from semicrystalline plastics to elastomers to hyperbranched amorphous waxes and oils. In addition to Brookhart's $\alpha$-diimine catalysts, iminopyridine $\mathrm{Ni}(\mathrm{II})$ complexes are among the most investigated systems. We report that $\mathrm{Ni}(\mathrm{II})$ complexes bearing aryliminopyridine ligands with bulky substituents both at the imino moiety and in the 6-position of pyridine afford either hyperbranched low molecular weight polyethylene oils or prevailingly linear crystalline polyethylenes or both, depending on the ligand structure and the reaction conditions. The formation of multiple active species in situ is suggested by analysis of the post-polymerization catalyst residues, showing the partial reduction of the imino function. Some related arylaminopyridine $\mathrm{Ni}(\mathrm{II})$ complexes were also synthesized and tested, showing a peculiar behavior, i.e., the number of branches of the produced polyethylenes increases while ethylene pressure increases.
\end{abstract}

Keywords: olefin polymerization; nickel; catalysts

\section{Introduction}

Following the breakthrough discoveries of $\mathrm{Ni}(\mathrm{II}) \alpha$-diimine catalysts by Brookhart et al. [1,2], a huge number of studies from both academia and industry focused on the development of new late-transition metal olefin polymerization catalysts over the last two decades. Among the large variety of ligand structural variations, the arylimino-pyridyl moiety was one of the most investigated, after the independent successful studies of penta-coordinate 2,6-bis(arylimino)pyridyl Fe(II) and $\mathrm{Co}$ (II) complexes by the groups of Brookhart [3] and Gibson [4]. In addition to catalysts supported by such tridentate [N,N,N] ligands, a large number of complexes of bidentate [N,N] iminopyridine ligands with divalent metals like $\mathrm{Fe}(\mathrm{II}), \mathrm{Co}(\mathrm{II})$, and especially $\mathrm{Ni}(\mathrm{II})$ and $\mathrm{Pd}(\mathrm{II})$ have been synthesized and tested in the polymerization of ethylene $[5,6]$ and in the copolymerization of ethylene with polar vinyl monomers, such as acrylates $[7,8]$. Simple modification of the steric and electronic features of the (imino)pyridine ligands and their usually easy preparation allowed a fine tuning of the polymerization/oligomerization performance of their metal complexes. E.g., limiting the discussion to $\mathrm{Ni}$ (II) complexes, early studies by Laine et al. [9] reported complexes bearing 2,6-alkyl-phenyl substituents on the imino moiety, producing nearly linear or moderately methyl branched low molecular weight polyethylenes (see Scheme 1A). Introduction of a methyl substituent in the 6-position of pyridine resulted in the production of a more linear polyethylene with slightly higher molecular weight and lower activity [10]. A related ligand modification introducing a 2,6-dialkylphenyl substituent in the 6-position of pyridine resulted in prevailing ethylene dimerization to 1-butene with minor amounts of C6, C8, and higher oligomers [11]. A large number of complexes with increasing steric bulk 
on the arylimino moiety of the ligand, e.g., o-benzhydryl, dibenzhydryl or dibenzocycloheptyl substituents but no substituents on the pyridine moiety, have been synthesized and tested by the group of Sun [12-18], resulting in thermally stable and highly active catalysts yielding low molecular weight moderately branched polyethylenes (Scheme 1B). Incorporation of very bulky 8-arylnaphtyl substituents on the imino moiety [19], blocking only one of the two coordination sites at the metal center, resulted in catalysts producing moderately branched polyethylenes with increased molecular weight $\left(\sim 10^{4} \mathrm{~g} \mathrm{~mol}^{-1}\right)$ (Scheme 1C).

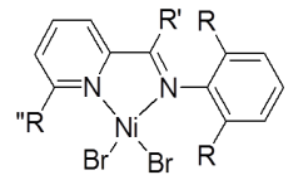

A

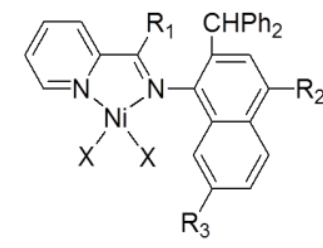

B

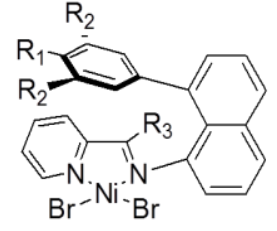

C

Scheme 1. Some relevant previously reported iminopyridine $\mathrm{Ni}(\mathrm{II})$ catalysts.: (A) arylimino-pyridine complexes [9-11]; (B) benzhydryl-substituted arylimino-pyridine complexes [14-16], and (C) "halfsandwich" pyridine-imine complexes [19].

In a previous paper [20], we reported the production of hyperbranched low molecular weight polyethylene oils by the iminopyridine complex 1 (see Scheme 2) activated by $\mathrm{AlEt}_{2} \mathrm{Cl}$. Both the typical degree of branching $(\approx 100$ branches per 1000 carbons) and the molecular weight of the produced samples $(\approx 1000 \mathrm{Da})$ were poorly sensitive to the reaction conditions. However, during that study, we noticed that when the polymerization was performed at high monomer pressure and low temperature (e.g., $45 \mathrm{~atm}$ and $20^{\circ} \mathrm{C}$ ), traces of solid polymer were obtained together with the low molecular weight polyethylene oils. We have now investigated complex $\mathbf{1}$ and some related Ni(II) complexes in ethylene polymerization also at sub-ambient temperature and high pressures, resulting in the production of solid polymers, in some cases consisting of fractions with different crystallinities, either as the only product or together with a methanol-soluble oily fraction. The possible role of the in situ formation of multiple active species owing to ligand structure modifications has been evaluated by analysis of the catalyst residues after the reaction and by the synthesis and testing of the corresponding aminopyridine $\mathrm{Ni}$ (II) complexes. For the latter catalysts, we have found a dependence of the branching degree on the ethylene pressure, which is opposite to that usually found, i.e., the number of branches increases at increasing pressure.
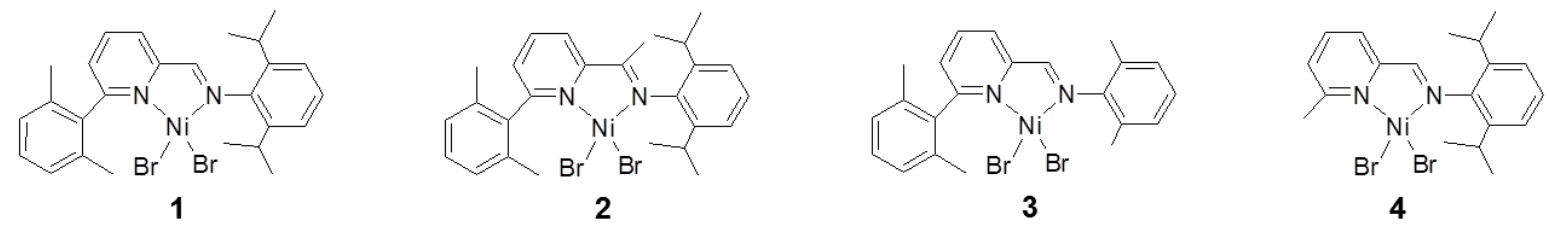

Scheme 2. Iminopyridine Ni complexes (1)-(4).

\section{Experimental Section}

2.1. General Conditions

All procedures sensitive to air or moisture were performed under a nitrogen atmosphere using standard Schlenk techniques. Glassware used were dried in an oven at $120^{\circ} \mathrm{C}$ overnight and exposed three times to vacuum-nitrogen cycles. Solvents were dried by refluxing over either $\mathrm{CaH}_{2}$ for dichloromethane or metallic sodium for toluene and $o$-dichlorobenzene and then distilled under nitrogen. Deuterated solvents were purchased from Aldrich and stored in the glovebox over $3 \AA$ molecular sieves before use. All other reagents were purchased from Aldrich and used as received. Ethylene was purchased from SON and used without further purification. 


\subsection{Characterization Methods}

\subsubsection{Nuclear Magnetic Resonance Spectroscopy (NMR)}

The NMR spectra were recorded on Bruker Advance 400 and Bruker $600 \mathrm{MHz}$ Ascend 3 HD spectrometers.

${ }^{1} \mathrm{H}$ NMR spectra are referenced using the residual solvent peak at $\delta 7.26$ for $\mathrm{CDCl}_{3}$ and $\delta: 6.93,7.19$ for $\mathrm{C}_{6} \mathrm{D}_{4} \mathrm{Cl}_{2} .{ }^{13} \mathrm{C}$ NMR spectra are referenced using the residual solvent peak at $\delta 77$. 16 for $\mathrm{CDCl}_{3}$ and $\delta: 127.19,130.04,132.39$ for $\mathrm{C}_{6} \mathrm{D}_{4} \mathrm{Cl}_{2}$.

\subsubsection{Size-Exclusion Chromatography (SEC)}

The molecular weights $\left(\mathrm{M}_{\mathrm{n}}\right.$ and $\left.\mathrm{M}_{\mathrm{w}}\right)$ and the molecular mass distribution $\left(\mathrm{M}_{\mathrm{w}} / \mathrm{M}_{\mathrm{n}}\right)$ of the oily hyperbranched oligoethylene samples were measured by Size-exclusion chromatography (SEC) at $30^{\circ} \mathrm{C}$, using THF as solvent, an eluent flow rate of $1 \mathrm{~mL} / \mathrm{min}$, and narrow polystyrene standards as reference. The measurements were performed on a Waters 1525 binary system equipped with a Waters 2414 RI detector using four Styragel columns (range 1000-1,000,000 $\AA$ ). Molecular weights $\left(M_{n}\right.$ and $\left.M_{w}\right)$ and polydispersities $\left(\mathrm{M}_{\mathrm{w}} / \mathrm{M}_{\mathrm{n}}\right)$ of crystalline polyethylene samples were determined by high-temperature size exclusion chromatography (HT-SEC) using Waters GPC-V200 RI detector at $135{ }^{\circ} \mathrm{C}$ using 1,2-dichlorobenzene as solvent and Styragel columns (range $1 \times 10^{7}-1 \times 10^{3}$ ).

\subsubsection{Differential Scanning Calorimetry (DSC)}

Melting points $\left(\mathrm{T}_{\mathrm{m}}\right)$ and crystallization points $\left(\mathrm{T}_{\mathrm{c}}\right)$ of the polymer samples were measured by DSC using aluminum pans and a DSC 2920 TA Instruments apparatus, calibrated with indium. Measurements were performed under nitrogen flow with a heating rate of $10{ }^{\circ} \mathrm{C} \mathrm{min}-1$ in the range of -100 to $+200{ }^{\circ} \mathrm{C}$. DSC data were processed with TA Universal Analysis v2.3 software and are reported for the second heating cycle.

\subsection{Ligands and Complexes Synthesis}

Ligands L1-L6 and complexes 1-4 were synthesized as described in our previous papers [20-22]. Complexes 5-6 were synthesized following a procedure previously reported for similar complexes [23].

\subsubsection{Synthesis of Complex 5}

To a solution of L5 (0.48 mmol, $0.180 \mathrm{~g})$ in dry dichloromethane, [(DME) $\mathrm{NiBr}_{2}$ ] $(0.43 \mathrm{mmol}, 0.133 \mathrm{~g})$ was added. The reaction mixture was stirred at room temperature for $16 \mathrm{~h}$. The solvent was removed under vacuum and the residues were washed with dry hexane and dried to obtain a green solid $(0.241 \mathrm{~g}, 95 \%$ yield $)$.

\subsubsection{Synthesis of Complex 6}

To a solution of L6 $(0.39 \mathrm{mmol}, 0.150 \mathrm{~g})$ in dry dichloromethane, [(DME) $\mathrm{NiBr}_{2}$ ] $(0.35 \mathrm{mmol}, 0.108 \mathrm{~g})$ was added. The reaction mixture was stirred at room temperature for $24 \mathrm{~h}$. The solvent was removed under vacuum and the residues were washed with dry hexane and dried to obtain a green solid $(0.196 \mathrm{~g}, 93 \%$ yield $)$.

\subsection{General Procedure for Ethylene Polymerization}

Ethylene polymerizations were carried out in a stainless-steel autoclave equipped with a magnetic stirrer. The reactor was first dried overnight at $120^{\circ} \mathrm{C}$ in an oven, cooled under vacuum, then pressurized with ethylene and vented three times. The reactor was thermostated at defined temperatures, charged with toluene, the catalyst and $\mathrm{AlEt}_{2} \mathrm{Cl}$ as cocatalyst and then pressurized at the prescribed ethylene pressure. The mixture was stirred for a defined time under constant ethylene pressure. Then the mixture was vented and poured into acidified methanol. The resulting solid (when present) was filtered. The solution was treated with hexane and water, then the organic layer was dried over $\mathrm{MgSO}_{4}$, filtered and the volatiles were distilled off in a rotavapor. The resulting waxy or oily residues were dried in vacuo overnight at $80^{\circ} \mathrm{C}$. 


\section{Results}

As mentioned in the Introduction, we have previously reported that complex 1 (see Scheme 2) promote ethylene polymerization after activation with $\mathrm{AlEt}{ }_{2} \mathrm{Cl}$ affording low molecular weight $\left(\mathrm{M}_{\mathrm{n}} \sim 10^{3} \mathrm{~g} / \mathrm{mol}\right)$ polyethylene oils under a variety of reaction conditions $\left(\mathrm{T}=20 \div 50{ }^{\circ} \mathrm{C}\right.$; ethylene pressure $\left.1 \div 50 \mathrm{~atm}\right)$ [20].

We have now tested complex 1 after activation with 200 equiv of $\mathrm{AlEt}_{2} \mathrm{Cl}$ under $50 \mathrm{~atm}$ of monomer pressure at $0{ }^{\circ} \mathrm{C}$ (see run 1, Table 1): under these conditions, a solid polymer was obtained as the prevailing product, in addition to the usual oily fraction recovered from the reaction solution (see the Experimental section for details). ${ }^{1} \mathrm{H}$ and ${ }^{13} \mathrm{C}$ NMR analysis of the solid and the liquid fractions (see Figures S1-S4) showed that the latter is a hyperbranched polyethylene similar to those previously reported [20], while the former is a moderately branched polyethylene containing prevalently methyl branches. DSC analysis of the solid polymer showed two melting endotherms, a broad one around $90{ }^{\circ} \mathrm{C}$ and a sharp one at $125^{\circ} \mathrm{C}$; similarly, two crystallization exotherms were observed (at 113 and $79^{\circ} \mathrm{C}$ ) when cooling the sample (see Figure S5). Changing the conditions of the DSC analysis (e.g., using different heating or cooling rates) did not affect the results. SEC analysis of the solid polymer indicated that the $\mathrm{M}_{\mathrm{w}}$ was one order of magnitude higher than that of the oily product and a rather broad polydispersity $(Đ=3.1)$.

Table 1. Ethylene polymerizations by complexes $1-4$.

\begin{tabular}{|c|c|c|c|c|c|c|c|c|c|}
\hline Run & Complex & $\mathrm{T}\left({ }^{\circ} \mathrm{C}\right)$ & $\mathbf{P}_{\text {(ethylene) }}$ (atm) & Time (h) & Yield (g) & Activity $^{a}$ & $M_{n}{ }^{b}(k D a)$ & $\mathrm{PDI}^{\mathrm{c}}$ & $\%$ Branches ${ }^{d}$ \\
\hline \multirow{2}{*}{$1^{\mathrm{e}}$} & \multirow{2}{*}{1} & \multirow{2}{*}{0} & \multirow{2}{*}{50} & \multirow{2}{*}{4} & $1.00^{\mathrm{f}}+$ & 25 & 0.9 & 3.1 & 6.2 \\
\hline & & & & & $2.80^{\mathrm{e}, \mathrm{g}}$ & 70 & 4.5 & 2.6 & 3.2 \\
\hline $2^{e}$ & 2 & 40 & 6 & 4 & $0.96^{\mathrm{f}}$ & 24 & 2.0 & 1.3 & 7.4 \\
\hline $3^{e}$ & 3 & 40 & 6 & 4 & $1.07^{\mathrm{f}}$ & 27 & 0.73 & 1.3 & 10.5 \\
\hline $4^{\mathrm{e}}$ & 4 & 40 & 6 & 4 & $1.4 \mathrm{~d}^{\mathrm{f}}$ & 35 & 0.35 & 1.2 & 9.0 \\
\hline $5^{h}$ & 2 & 40 & 10 & 4 & $4.58^{\mathrm{f}}$ & 114 & 3.6 & 1.4 & 7.3 \\
\hline $6^{\mathrm{h}}$ & 2 & 40 & 30 & 20 & $11.0^{\mathrm{f}}$ & 55 & 3.10 & 1.4 & 8.2 \\
\hline $7^{h}$ & 3 & 40 & 10 & 4 & $5.21^{\mathrm{f}}$ & 130 & 0.58 & 1.3 & 8.9 \\
\hline $8^{h}$ & 4 & 40 & 10 & 4 & $4.15^{\mathrm{f}}$ & 104 & 0.30 & 1.1 & 8.8 \\
\hline $9^{e}$ & 2 & 0 & 50 & 4 & $0.91^{e, g}$ & 23 & 5.20 & 3.2 & 5.0 \\
\hline
\end{tabular}

${ }^{a}$ Activity in $\mathrm{kg} \mathrm{mol}_{[\mathrm{Ni}]}{ }^{-1} \mathrm{~h}^{-1}$. ${ }^{\mathrm{a}, \mathrm{b}}$ Determined from the ratio between total resonance integral and unsaturated end group intensity in the ${ }^{1} \mathrm{H}$ NMR spectra [24]. ${ }^{\mathrm{c}}$ Determined by size exclusion chromatography (SEC) vs. polystyrene standards. ${ }^{\mathrm{d}}$ Determined from ${ }^{1} \mathrm{H}$ NMR spectra [24]. ${ }^{\mathrm{e}}$ Polymerization conditions: Ni catalyst $=10 \mu \mathrm{mol}$ (dissolved in $2 \mathrm{~mL}$ of o-dichlorobenzene), AlEt $\mathrm{Cl}_{\mathrm{Co}} \mathrm{catalyst}=2 \mathrm{mmol}$, solvent $=50 \mathrm{~mL}$ toluene. ${ }^{\mathrm{f}}$ Low-molecular weight polyethylene oil recovered from the reaction mixture. ${ }^{\mathrm{g}}$ Solid polyethylene precipitated in methanol. ${ }^{\mathrm{h}}$ Polymerization conditions: Ni catalyst $=10 \mu \mathrm{mol}$ (dissolved in $2 \mathrm{~mL}$ of dichloromethane), $\mathrm{AlEt}_{2} \mathrm{Cl} \mathrm{co}_{\mathrm{catalyst}}=2 \mathrm{mmol}$, solvent $=20 \mathrm{~mL}$ toluene.

The solid polymer sample was, thus, fractioned using boiling heptane in a Kumagawa extractor, resulting in a soluble (75\%) and an insoluble (25\%) fraction: the latter was analyzed by ${ }^{1} \mathrm{H}$ and ${ }^{13} \mathrm{C}$ NMR, indicating a substantially linear polyethylene (methyl branches $<1 \%$ ) with no detectable unsaturated end groups (see Figures S6 and S7); accordingly, DSC analysis showed only a melting endotherm at $130{ }^{\circ} \mathrm{C}$ (Figure S8). The heptane-soluble fraction was analyzed similarly, resulting a more branched, lower melting polyethylene (Figure S9).

Subsequently, we have tested several related complexes bearing different substituents at the pyridino and at the imino moieties (complexes 2-4, see Scheme 2).

Complexes (2)-(4) were initially tested in the homopolymerization of ethylene after activation with $\mathrm{AlEt}_{2} \mathrm{Cl}$ (200 equiv) at $40{ }^{\circ} \mathrm{C}$ and $6 \mathrm{~atm}$ monomer pressure (see Table 1 , runs 2-4): under these reaction conditions, all the complexes afforded hyperbranched low molecular weight polyethylene oils, soluble in methanol, similar to those produced by complex 1 [20].

Characterization of the polymer samples by ${ }^{1} \mathrm{H}$ and ${ }^{13} \mathrm{C}$ NMR analyses is reported in the Supplementary Material. As observed for 1, multigram-quantities of low molecular weight polyethylene oils were obtained under higher catalyst and monomer concentrations 
and for longer reaction times, suggesting that the catalysts are stable under these conditions (see runs 5-8). Complexes 2, bearing a ketimino ligand, afforded polyethylenes having higher molecular weights (see runs 2, 5, 6, Table 1 ) with respect to that produced by the previously reported corresponding aldimino complex 1 [20].

Complex 2 was then tested under $50 \mathrm{~atm}$ of monomer pressure at $0{ }^{\circ} \mathrm{C}$ (see run 9 , Table 1): in this case, only a solid polymer was produced, while no oily product was recovered from the reaction mixture. NMR analysis indicated a moderately branched polyethylene (5\% branches, see Figures S12 and S13), while DSC showed very broad melting endotherms centered around 32 and $71^{\circ} \mathrm{C}$ and very broad crystallization exotherms centered around 57 and $24^{\circ} \mathrm{C}$ (see Figure S14).

The production of fractions of macromolecules with different structures and molecular weights suggest that different active species can be generated in situ by activation with $\mathrm{AlEt}_{2} \mathrm{Cl}$. With the aim to shed some light on the latter hypothesis, two polymerization runs were carried out using complexes 2 and 3 activated by $\mathrm{AlEt}_{2} \mathrm{Cl}$ at $0{ }^{\circ} \mathrm{C}$ under $1 \mathrm{~atm}$ of ethylene for $1 \mathrm{~h}$ (see Scheme 3). The reactions were quenched with acidified methanol, and water was added; the mixtures were extracted with dichloromethane and, after solvent removal, the crude product was filtered through a silica column and eluted with hexane and then dichloromethane. The product isolated from the filtrate was analyzed by ${ }^{1} \mathrm{H} \mathrm{NMR}$, showing the presence of both the imine ligands and the corresponding amines deriving by imine reduction. Interestingly, ligand modification after the polymerization run was more relevant for the aldimine complex 3 than for the ketimine complex 2, since the fraction of produced amine was $11 \%$ for the former and only $5 \%$ for the latter. Moreover, performing the same experiment at higher temperature $\left(40^{\circ} \mathrm{C}\right)$ using the ketimine complex 2 resulted in the formation of $22 \%$ of amine (see Figures S15 and S16). Following the suggestion of the reviewer, we have performed a control experiment in the absence of ethylene, resulting in the production of the original imino and the reduced amino ligands, as observed in the presence of ethylene, and an additional amine species bearing an ethyl group on the carbon in alpha position with respect to $\mathrm{N}$ atom (see Figure S17) [25].

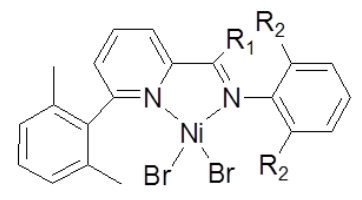

2: $\mathrm{R}_{1}=\mathrm{CH}_{3}, \mathrm{R}_{2}=\mathrm{CH}\left(\mathrm{CH}_{3}\right)_{2}$ 3: $\mathrm{R}_{1}=\mathrm{H}, \mathrm{R}_{2}=\mathrm{CH}_{3}$

\section{1: $\mathrm{AlEt}_{2} \mathrm{Cl}$, Toluene, $1 \mathrm{~h}$, atm of ethylene \\ 2: $\mathrm{CH}_{3} \mathrm{OH}, \mathrm{HCl}, \mathrm{H}_{2} \mathrm{O}$}
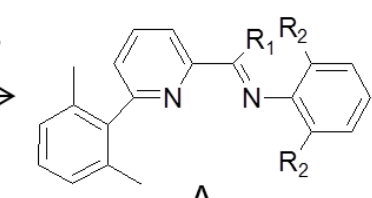

A

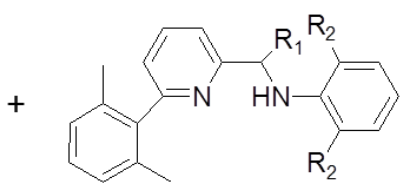

B

\begin{tabular}{|c|c|c|c|}
\hline & $\mathrm{T}\left({ }^{\circ} \mathrm{C}\right)$ & $\% \mathrm{~A}$ & $\% \mathrm{~B}$ \\
\hline $\mathbf{2}$ & 40 & 78 & 22 \\
$\mathbf{2}$ & 0 & 95 & 5 \\
$\mathbf{3}$ & 0 & 89 & 11 \\
\hline
\end{tabular}

Scheme 3. Investigation of the post-polymerization catalyst fate.

Following the above findings, we decided to synthesize the authentic amine $\mathrm{Ni}$ complexes 5 and $\mathbf{6}$ (see Scheme 4) having ligand structures corresponding to the imine complexes $\mathbf{1}$ and 2, respectively. The complexes were obtained in good yields by allowing us to react the amine ligands and dimethoxyethane nickel dibromide in $\mathrm{CH}_{2} \mathrm{Cl}_{2}$ at room temperature for $16 \mathrm{~h}$ (see the Experimental section).

Pyridilamino complex 5, after activation with $\mathrm{AlEt}_{2} \mathrm{Cl}$, was tested in the polymerization of ethylene at $0{ }^{\circ} \mathrm{C}$ under $50 \mathrm{~atm}$ of monomer, resulting in the exclusive production of low molecular weight highly branched polyethylene oils (see run 10, Table 2). In contrast, the corresponding pyridylimino complex 1 under similar conditions (although using higher dilution, see the Experimental Section) produced a mixture of solid polyethylene and an oily fraction, with significantly higher yield (cf. run 1, Table 1). Pyridylamino complex 6 under the same conditions also afforded low molecular weight highly branched 
polyethylene oils, although in very low amount (see run 11, Table 2). Complexes 5 and 6 were also tested at $\mathrm{T}=40^{\circ} \mathrm{C}$ under either 10 or $50 \mathrm{~atm}$ of ethylene pressure: in all cases low yields of hyperbranched polyethylene oils were obtained. Interestingly, for both catalysts the branching degree was higher at $50 \mathrm{~atm}$ than at $10 \mathrm{~atm}$ (cf. run 12 vs. run 13 and run 14 vs. run 15), at variance with all the literature results reported for $\mathrm{Ni}(\mathrm{II})$ catalysts affording branched polyethylenes via a "chain walking" mechanism [2].

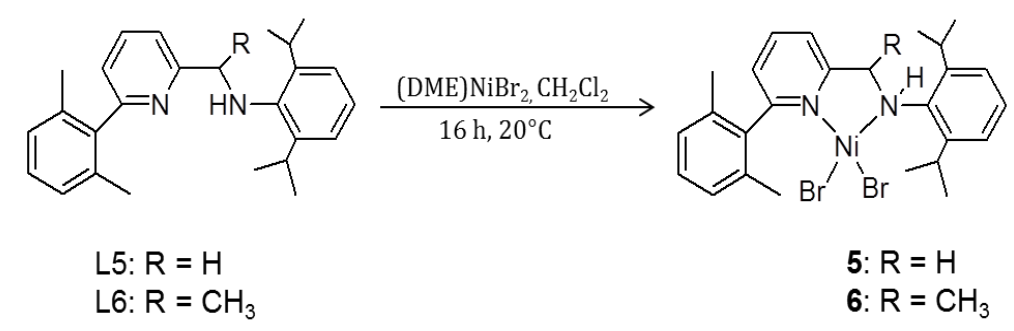

Scheme 4. Synthesis of pyridylamino complexes 5 and 6.

Table 2. Ethylene polymerization by aminopyridine complexes 5 and $\mathbf{6}$.

\begin{tabular}{|c|c|c|c|c|c|c|c|}
\hline Run $^{a}$ & Complex & Temperature $\left({ }^{\circ} \mathrm{C}\right)$ & $P($ atm) & Yield (g) & Activity $^{b}$ & $M_{n}^{c}(k D a)$ & $\%$ Branches $^{d}$ \\
\hline 10 & 5 & 0 & 50 & 0.11 & 3.0 & 2.2 & 20.4 \\
\hline 11 & 6 & 0 & 50 & 0.02 & 0.5 & 4.9 & 8.8 \\
\hline 12 & 5 & 40 & 10 & 0.06 & 1.5 & 4.5 & 13.3 \\
\hline 13 & 5 & 40 & 50 & 0.20 & 5.0 & 5.8 & 29.8 \\
\hline 14 & 6 & 40 & 10 & 0.05 & 1.2 & 3.3 & 12.4 \\
\hline 15 & 6 & 40 & 50 & 0.10 & 2.5 & 4.6 & 21.9 \\
\hline
\end{tabular}

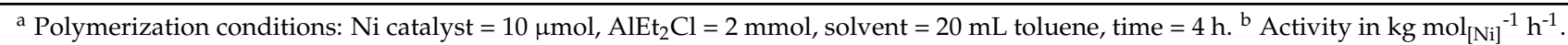
${ }^{c}$ Determined from ratio between total resonance integral and unsaturated end group intensity in the ${ }^{1} \mathrm{H}$ NMR spectra [24]. ${ }^{d}$ Determined from ${ }^{1} \mathrm{H}$ NMR spectra [24].

\section{Discussion}

It is well known that $\mathrm{Ni}(\mathrm{II})$ catalysts operate via a "chain-walking" mechanism of polymerization, involving a number of $\beta$-hydride eliminations and reinsertions with opposite regiochemistry: in this way, a variable content of branches of different lengths are introduced in the polymer chain [2]. As established in the literature, the degree of branching depends on temperature, monomer pressure, and catalyst structure: higher branching is favored by higher polymerization temperature, lower monomer pressure and larger steric bulk in the axial positions of the square-planar coordination sphere [1,2,26-30]. So, very different products can be obtained from polymerization of ethylene only, ranging from substantially linear and crystalline materials to elastomers to hyperbranched polyethylene waxes and oils $[1,2,26-31]$.

However, the above framework cannot explain the concomitant production of the different types of macromolecules that we have observed in the above reported polymerization runs by our $\mathrm{Ni}(\mathrm{II})$ catalysts bearing aryliminopyridine ligands with bulky substituents both at the imino moiety and in the 6-position of pyridine. On the other hand, there are many literature examples pointing to the easy modification in situ of olefin polymerization catalysts based on imino complexes activated by aluminum alkyls [32-35], resulting in the reduction of the imino functionality. Moreover, Gibson reported examples of reactions of $\alpha$-diimine and pyridylimine ligands with, e.g., $\mathrm{AlMe}_{3}$, resulting in $\mathrm{Al}$ imino-amide and pyridyl-amide complexes arising from methyl group transfer from the aluminium centre to the backbone carbon of the imine ligand [34]. So, it is reasonable to hypothesize that multiple active species are generated under the examined conditions.

As a matter of fact, our experiments analyzing the fate of the iminopyridine $\mathrm{Ni}$ (II) catalysts after the polymerization run showed the partial transformation of the original ligands in the corresponding aminopyridines. This finding supports the multi-site nature of our catalyst systems, at least under certain conditions. 
Looking for some further evidence on the matter, we have synthesized and tested two aminopyridine $\mathrm{Ni}(\mathrm{II})$ complexes ( 5 and $\mathbf{6}$ ) having structures similar to the iminopyridine complexes $\mathbf{2}$ and $\mathbf{3}$. While aminopyridine $\mathrm{Ni}$ (II) complexes have been previously reported as efficient ethylene polymerization catalysts [36,37], only traces of uncharacterized oligomers were obtained using aminopyridine complexes having aryl groups in the 6-position of the pyridine moiety, similar to 5 and 6 [37].

Our polymerization results have shown that, under similar conditions $\left(\mathrm{T}=0{ }^{\circ} \mathrm{C}\right.$, $\mathrm{P}=50 \mathrm{~atm}$ ), the aminopyridine complexes produce only low amounts of hyperbranched polyethylene oils, while the iminopyridine analogs afford mixtures of different types of macromolecules (see above), again suggesting the possible modification of the imino functionality. Interestingly, for the aminopyridine complexes more branched polyethylenes are produced at higher monomer pressure, at variance with the usual behavior of $\mathrm{Ni}$ (II) catalysts. The latter could be an interesting feature, since one of the main limitations of Brookhart's Ni(II) catalysts for practical applications in the field of elastomeric materials obtained by ethylene feed only (without the need of comonomers such as propene or 1-hexene) is the fact that the polymers obtained under the high pressures required by the industrial processes are substantially linear. Further investigation in this direction is in progress in our laboratories.

Supplementary Materials: The following are available online at https:/ /www.mdpi.com/article/10 $.3390 /$ macromol1020010/s1, Figure S1: ${ }^{1} \mathrm{H}-\mathrm{NMR}$ spectrum of an oily hyperbranched oligoethylene sample, Figure S2: ${ }^{13} \mathrm{C}-\mathrm{NMR}$ spectrum of an oily hyperbranched oligoethylene sample, Figure S3: ${ }^{1} \mathrm{H}-\mathrm{NMR}$ spectrum of a crystalline polyethylene sample, Figure S4: ${ }^{13} \mathrm{C}-\mathrm{NMR}$ spectrum of a crystalline polyethylene sample, Figure S5: DSC thermogram of a crystalline polyethylene sample, Figure S6: ${ }^{1} \mathrm{H}-\mathrm{NMR}$ spectrum of the heptane-insoluble part of a crystalline polymer sample, Figure S7: ${ }^{13} \mathrm{C}-\mathrm{NMR}$ spectrum of the heptane-insoluble part of a crystalline polymer sample, Figure S8: DSC thermogram of the heptane-insoluble fraction of a crystalline polymer sample, Figure S9: DSC thermogram of the heptane-soluble fraction of a crystalline polymer sample, Figure S10: ${ }^{1} \mathrm{H}-\mathrm{NMR}$ spectrum of a typical low MW oily polyethylene sample, Figure S11: ${ }^{13} \mathrm{C}-\mathrm{NMR}$ spectrum of a typical low MW oily polyethylene sample, Figure S12: ${ }^{1} \mathrm{H}-\mathrm{NMR}$ spectrum of a crystalline polyethylene sample, Figure S13: ${ }^{13} \mathrm{C}-\mathrm{NMR}$ spectrum of a crystalline polyethylene sample, Figure S14: DSC thermogram of a crystalline polyethylene sample, Figure S15: ${ }^{1} \mathrm{H}-\mathrm{NMR}$ spectra of the products of reaction between complex 3 and $\mathrm{AlEt}_{2} \mathrm{Cl}$, Figure S16: ${ }^{1} \mathrm{H}-\mathrm{NMR}$ spectra of the products of reaction between complex 2 and $\mathrm{AlEt}_{2} \mathrm{Cl}$.

Author Contributions: Conceptualization, C.P.; methodology, C.P. and I.D.; investigation, Z.S. and I.D.; data curation, Z.S. and I.D.; writing —original draft preparation, C.P. and I.D.; writing—review and editing, C.P.; supervision, C.P.; project administration, C.P.; funding acquisition, C.P. All authors have read and agreed to the published version of the manuscript.

Funding: This research was funded by the University of Salerno, grant FARB 2017.

Institutional Review Board Statement: Not applicable.

Informed Consent Statement: Not applicable.

Data Availability Statement: The data presented in this study are available on request from the corresponding author.

Acknowledgments: The authors acknowledge the technical assistance of Patrizia Oliva for NMR experiments.

Conflicts of Interest: The authors declare no conflict of interest.

\section{References}

1. Johnson, L.K.; Killian, C.M.; Brookhart, M. New Pd(II)- and Ni(II)-Based Catalysts for Polymerization of Ethylene and $\alpha$-Olefins. J. Am. Chem. Soc. 1995, 117, 6414-6415. [CrossRef]

2. Ittel, S.D.; Johnson, L.K.; Brookhart, M. Late-Metal Catalysts for Ethylene Homo- and Copolymerization. Chem. Rev. 2000, 100, 1169-1203. [CrossRef] [PubMed] 
3. Small, B.L.; Brookhart, M.; Bennett, A.M.A. Highly Active Iron and Cobalt Catalysts for the Polymerization of Ethylene. J. Am. Chem. Soc. 1998, 120, 4049-4050. [CrossRef]

4. Britovsek, G.J.P.; Gibson, V.C.; Hoarau, O.D.; Spitzmesser, S.K.; White, A.J.P.; David, J.; Williams, D.J. Iron and Cobalt Ethylene Polymerization Catalysts: Variations on the Central Donor. Inorg. Chem. 2003, 42, 3454-3465. [CrossRef]

5. Bianchini, C.; Giambastiani, G.; Luconi, L.; Meli, A. Olefin oligomerization, homopolymerization and copolymerization by late transition metals supported by (imino) pyridine ligands. Coord. Chem. Rev. 2010, 254, 431-455. [CrossRef]

6. Wang, Z.; Liu, Q.; Solan, G.A.; Sun, W.-H. Recent advances in Ni-mediated ethylene chain growth: N-Imine-Donor ligand effects on catalytic activity, thermal stability and oligo-/polymer structure. Coord. Chem. Rev. 2017, 350, 68-83. [CrossRef]

7. Wang, F.; Chen, C. A continuing legend: The Brookhart-type $\alpha$-diimine nickel and palladium catalysts. Polym. Chem. 2019, 10, 2354-2369. [CrossRef]

8. Guo, L.; Liu, W.; Chen, C. Late transition metal catalyzed $\alpha$-olefin polymerization and copolymerization with polar monomers. Mater. Chem. Front. 2017, 1, 2487-2494. [CrossRef]

9. Laine, T.V.; Klinga, M.; Leskelä, M. Synthesis and X-ray Structures of New Mononuclear and Dinuclear Diimine Complexes of Late Transition Metals. Eur. J. Inorg. Chem. 1999, 1999, 959-964. [CrossRef]

10. Laine, T.V.; Piironen, U.; Lappalainen, K.; Klinga, M.; Aitola, E.; Leskelä, M. Pyridinylimine-Based nickel(II) and palladium(II) complexes: Preparation, structural characterization and use as alkene polymerization catalysts. J. Organomet. Chem. 2000, 606, 112-124. [CrossRef]

11. Irrgang, T.; Keller, S.; Maisel, H.; Kretschmer, W.; Kempe, R. Sterically Demanding Iminopyridine Ligands. Eur. J. Inorg. Chem. 2007, 2007, 4221-4228. [CrossRef]

12. Mahmood, Q.; Sun, W.-H. N, N-Chelated nickel catalysts for highly branched polyolefin elastomers: A survey. R. Soc. Open Sci. 2018, 5, 180367. [CrossRef]

13. Vignesh, A.; Zhang, Q.; Ma, Y.; Liang, T.; Sun, W.-H. Attaining highly branched polyethylene elastomers by employing modified $\alpha$-diiminonickel(II) catalysts: Probing the effects of enhancing fluorine atom on the ligand framework towards mechanical properties of polyethylene. Polymer 2020, 187, 122089. [CrossRef]

14. Sun, W.-H.; Song, S.; Li, B.; Redshaw, C.; Hao, X.; Li, Y.-S.; Wang, F. Ethylene polymerization by 2-iminopyridylnickel halide complexes: Synthesis, characterization and catalytic influence of the benzhydryl group. Dalton Trans. 2012, 41, 11999-12010. [CrossRef]

15. Yue, E.; Xing, Q.; Zhang, L.; Shi, Q.; Cao, X.-P.; Wang, L.; Redshaw, C.; Sun, W.-H. Synthesis and characterization of 2-(2benzhydrylnaphthyliminomethyl) pyridylnickel halides: Formation of branched polyethylene. Dalton Trans. 2014, 43, 3339-3346. [CrossRef]

16. Yue, E.; Zhang, L.; Xing, Q.; Cao, X.-P.; Hao, X.; Redshaw, C.; Sun, W.-H.; Sun, W.-H. 2-(1-(2-Benzhydrylnaphthylimino) ethyl)-pyridylnickel halides: Synthesis, characterization and ethylene polymerization behavior. Dalton Trans. 2014, 43, 423-431. [CrossRef] [PubMed]

17. Zeng, Y.; Mahmood, Q.; Hao, X.; Sun, W.-H. Synthesis and Ethylene Polymerization of 8-(fluorenylarylimino)-5, 6, 7Trihydroquinolylnickel Chlorides: Tailoring Polyethylenes by Adjusting Fluorenyl Position and Adduct Et 2 Zn. J. Polym. Sci. Part A Polym. Chem. 2017, 55, 1910-1919. [CrossRef]

18. Zada, M.; Vignesh, A.; Guo, L.; Zhang, R.; Zhang, W.; Ma, Y.; Sun, Y.; Sun, W.-H. Sterically and Electronically Modified Aryliminopyridyl-Nickel Bromide Precatalysts for an Access to Branched Polyethylene with Vinyl/Vinylene End Groups. ACS Omega 2020, 5, 10610-10625. [CrossRef] [PubMed]

19. Chen, Z.; Allen, K.E.; White, P.S.; Daugulis, O.; Brookhart, M. Synthesis of Branched Polyethylene with "Half-Sandwich" Pyridine-Imine Nickel Complexes. Organometallics 2016, 35, 1756-1760. [CrossRef]

20. D'Auria, I.; Milione, S.; Caruso, T.; Balducci, G.; Pellecchia, C. Synthesis of hyperbranched low molecular weight polyethylene oils by an iminopyridine nickel(II) catalyst. Polym. Chem. 2017, 8, 6443-6454. [CrossRef]

21. D'Auria, I.; D'Alterio, M.C.; Talarico, G.; Pellecchia, C. Alternating Copolymerization of $\mathrm{CO}_{2}$ and Cyclohexene Oxide by New Pyridylamidozinc(II) Catalysts. Macromolecules 2018, 51, 9871-9877. [CrossRef]

22. Saki, Z.; D'Auria, I.; Dall'Anese, A.; Milani, B.; Pellecchia, C. Copolymerization of Ethylene and Methyl Acrylate by Pyridylimino $\mathrm{Ni}(\mathrm{II})$ Catalysts Affording Hyperbranched Poly(ethylene-co-methylacrylate)s with Tunable Structures of the Ester Groups. Macromolecules 2020, 53, 9294-9305. [CrossRef]

23. Hu, H.; Zhang, L.; Gao, H.; Zhu, F.; Wu, Q. Design of Thermally Stable Amine-Imine Nickel Catalyst Precursors for Living Polymerization of Ethylene: Effect of Ligand Substituents on Catalytic Behavior and Polymer Properties. Chem. Eur. J. 2014, 20, 3225-3233. [CrossRef]

24. Wiedemann, T.; Voit, G.; Tchernook, A.; Roesle, P.; Götter-Schnetmann, I.; Mecking, S. Monofunctional Hyperbranched Ethylene Oligomers. J. Am. Chem. Soc. 2014, 136, 2078-2085. [CrossRef] [PubMed]

25. Gibson, V.C.; Redshaw, C.; White, A.J.P.; Williams, D.J. Synthesis and structural characterisation of aluminium imino-amide and pyridyl-amide complexes: Bulky monoanionic N, N chelate ligands via methyl group transfer. J. Organomet. Chem. 1998, 550, 453-456. [CrossRef]

26. Gibson, V.C.; Spitzmesser, S.K. Advances in Non-Metallocene Olefin Polymerization Catalysis. Chem. Rev. 2003, 103, 283-316. [CrossRef] [PubMed]

27. Delferro, M.; Marks, T.J. Multinuclear Olefin Polymerization Catalysts. Chem. Rev. 2011, 111, 2450-2485. [CrossRef] 
28. Sun, W.-H. Novel polyethylenes via late transition metal complex pre-catalysts. Adv. Polym. Sci. 2013, 258, 163-178.

29. Mu, H.; Pan, L.; Song, D.; Li, Y. Neutral Nickel Catalysts for Olefin Homo- and Copolymerization: Relationships between Catalyst Structures and Catalytic Properties. Chem. Rev. 2015, 115, 12091-12137. [CrossRef] [PubMed]

30. Guo, L.; Dai, S.; Sui, X.; Chen, C. Palladium and nickel catalyzed chain walking olefin polymerization and copolymerization. ACS Catal. 2016, 6, 428-441. [CrossRef]

31. D'Auria, I.; Maggio, M.; Guerra, G.; Pellecchia, C. Efficient Modulation of Polyethylene Microstructure by Proper Activation of ( $\alpha$-Diimine) Ni(II) Catalysts: Synthesis of Well-Performing Polyethylene Elastomers. Macromolecules 2017, 50, 6586-6594. [CrossRef]

32. Saito, J.; Onda, M.; Matsui, S.; Mitani, M.; Furuyama, R.; Tanaka, H.; Fujita, T. Propylene Polymerization with Bis(phenoxy-imine) Group-4 Catalysts Using ${ }^{i} \mathrm{Bu}_{3} \mathrm{Al} / \mathrm{Ph}_{3} \mathrm{CB}\left(\mathrm{C}_{6} \mathrm{~F}_{5}\right)_{4}$ as a Cocatalyst. Macromol. Rapid Commun. 2002, 23, 1118-1123. [CrossRef]

33. Yasuhiko, S.; Norio, K.; Fujita, T. Synthesis and Ethylene Polymerization Behavior of a New Titanium Complex Having Two Imine-Phenoxy Chelate Ligands. Chem. Lett. 2002, 31, 358-359.

34. Vishwa, P.A.; Haruyuki, M.; Junji, S.; Mitsuhiko, O.; Fujita, T. Highly Isospecific Polymerization of Propylene with Bis(phenoxyimine) $\mathrm{Zr}$ and $\mathrm{Hf}$ Complexes Using ${ }^{i} \mathrm{Bu}_{3} \mathrm{Al} / \mathrm{Ph}_{3} \mathrm{CB}\left(\mathrm{C}_{6} \mathrm{~F}_{5}\right)_{4}$ as a Cocatalyst. Chem. Lett. 2004, 33, 250-251.

35. Lamberti, M.; Consolmagno, M.; Mazzeo, M.; Pellecchia, C. A Binaphthyl-Bridged Salen Zirconium Catalyst Affording Atactic Poly(propylene) and Isotactic Poly ( $\alpha$-olefins). Macromol. Rapid Commun. 2005, 26, 1866-1871. [CrossRef]

36. Zai, S.; Liu, F.; Gao, H.; Li, C.; Zhou, G.; Cheng, S.; Guo, L.; Zhang, L.; Zhu, F.; Wu, Q. Longstanding living polymerization of ethylene: Substituent effect on bridging carbon of 2-pyridinemethanamine nickel catalysts. Chem. Commun. 2010, 46, 4321-4323. [CrossRef]

37. Zai, S.; Gao, H.; Huang, Z.; Hu, H.; Wu, H.; Wu, Q. Substituent Effects of Pyridine-amine Nickel Catalyst Precursors on Ethylene Polymerization. ACS Catal. 2012, 2, 433-440. [CrossRef] 